\title{
Determination of Crystallization Kinetics and Size Distribution Parameters of Agglomerated Calcium Carbonate Nanoparticles during the Carbonation of a Suspension of Lime
}

\author{
Mathilde Schnebelen ${ }^{1,2 *}$, Myriam Ricaud ${ }^{3}$, Alexandra Jakob ${ }^{2}$, Didier Sy², Edouard Plasari ${ }^{1}$, \\ Hervé Muhr ${ }^{1}$ \\ ${ }^{1}$ Laboratoire Réactions et Génie des Procédés, Université de Lorraine, Nancy, France \\ ${ }^{2}$ Solvay Spécialités France, Salin de Giraud, France \\ ${ }^{3}$ Groupe Dynamique des Phases condensées, Université des Sciences et Techniques du Languedoc de \\ Montpellier 2, Montpellier, France \\ Email: ${ }^{*}$ mathilde.schnebelen@univ-lorraine.fr
}

Received 9 March 2015; accepted 12 May 2015; published 18 May 2015

Copyright (C) 2015 by authors and Scientific Research Publishing Inc.

This work is licensed under the Creative Commons Attribution International License (CC BY).

http://creativecommons.org/licenses/by/4.0/

(c) (i) Open Access

\begin{abstract}
The reaction studied in this work is the synthesis of nanometric size calcium carbonate by carbonation of a suspension of lime, which represents the most common industrial route. The carbonation was proceeded in a pilot batch reactor. This article presents a method for the determination of nucleation and crystal growth rates of calcium carbonate by following two macroscopic parameters: the mass production rate by precipitation and the specific surface area. The results give a constant nucleation rate around $4 \times 10^{15} \mathrm{~m}^{-3} \cdot \mathrm{s}^{-1}$ and a decreasing crystal growth rate between 0.2 and $2 \times 10^{-10} \mathrm{~m} \cdot \mathrm{s}^{-1}$. It also provides the main characteristics of the monoparticle size distributions (i.e. the mean particle sizes and in situ coefficient of variation) in the agglomerates, which cannot be obtained by other known methods. For the carbonation carried out in this work, the mean mass particle size at the end of the reaction is about $300 \mathrm{~nm}$ and the coefficient of variation of $0.28 \mathrm{in}$ dicates a narrow particle size distribution of the monoparticles.
\end{abstract}

\section{Keywords}

Calcium Carbonate, Nucleation Rate, Crystal Growth Rate, Lime Carbonation

\footnotetext{
${ }^{*}$ Corresponding author.
}

How to cite this paper: Schnebelen, M., et al. (2015) Determination of Crystallization Kinetics and Size Distribution Parameters of Agglomerated Calcium Carbonate Nanoparticles during the Carbonation of a Suspension of Lime. Crystal Structure Theory and Applications, 4, 16-27. http://dx.doi.org/10.4236/csta.2015.42003 


\section{Introduction}

Precipitated calcium carbonate (PCC) is a mineral filler of various applications in paints, sealants, paper, ink, pharmacy, cosmetic, food etc. It can be industrially synthetized through several ways but the most common is the carbonation route. It consists in bubbling carbon dioxide in a suspension of lime to get particles of precipitated calcium carbonate.

This reaction has been studied in the literature from different points of view. References [1] and [2] studied the carbonation of a suspension of lime and focused on the aspect of the gas liquid reaction. Reference [3] used the film and the penetration theory [4] to describe the effects of the chemical reaction on the mean particle size. Reference [5] worked on the influence of the $\mathrm{pH}$ and the conductivity on the precipitation. As for [6]-[8], they examined the agglomeration of calcium carbonate particles but not during the carbonation under industrial complex conditions characterized by high solid phase concentration of calcium hydroxide and calcium carbonate and intensive gas bubbling.

For what our system concerns, some important macroscopic parameters can be followed against time during the precipitation reaction, in particular the PCC produced mass and the specific surface area of the PCC particles. The monoparticles are agglomerated, but the agglomerates are "loose". In such a case, during precipitation, the solution is in contact with all elementary particles which make up the agglomerates, so that they can grow in the same way as single crystals in the suspension and consequently the agglomeration does not influence the specific surface area [9]. The laser diffraction granulometer can not measure the particle size distribution of calcium carbonate monoparticles. Nevertheless, the produced mass and the specific surface area are variables depending on monoparticle size distribution, so it is interesting to see if these data can be used to extract the nucleation and crystal growth rates as a function of precipitation time. Thus the aim of the work is to present a method for the determination of nucleation and crystal growth rates of calcium carbonate and some other monoparticle size distribution characteristics from the monitoring of these two macroscopic parameters.

\section{Experimental}

\subsection{Experimental Set up}

The experimental pilot scale installation (Figure 1) is composed of a six liters glass jacketed batch reactor and all necessary equipment and instruments to follow the reaction parameters (temperatures $\mathrm{T}$, $\mathrm{pH}$, gas flowrate $\mathrm{Q}_{\mathrm{m}}$ and conductivity of the suspension $\chi$ ).

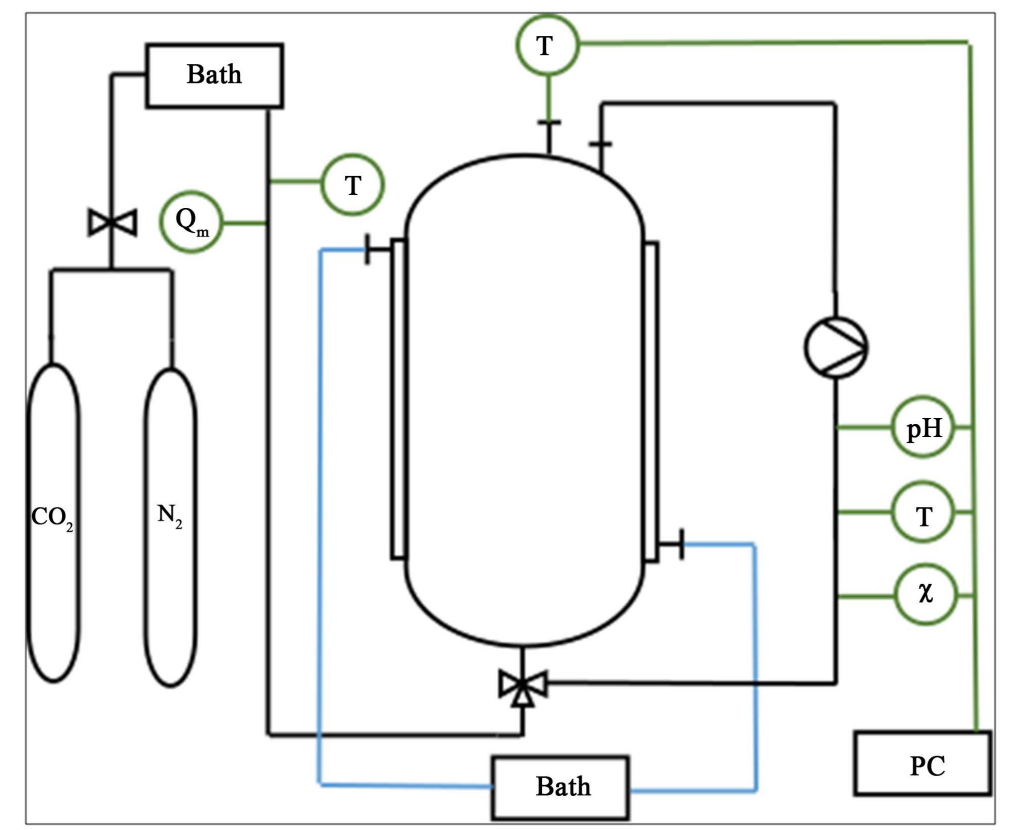

Figure 1. Pilot scheme. 
The $\mathrm{pH}$ sensor used in this work is an industrial model InPro 4800i SG (reference source Ag/AgCl) provided by Mettler Toledo. It is combined with a temperature sensor Platinum 1000 to compensate the modification of temperature. The sensor is calibrated before each experiment thanks to two buffer solutions ( $\mathrm{pH} 7.00$ and 10.00 furnished by Fluka) and with the help of the software iSensLight and a pH transmitter M700 both from Mettler Toledo.

The reactor is provided in gas thanks to two bottles $\left(\mathrm{CO}_{2}\right.$ and $\left.\mathrm{N}_{2}\right)$. The temperatures of the gas and the water in the jacket are adjusted with two thermo-regulated baths, respectively for the suspension and the gas.

\subsection{Experimental Operations}

The reactor is filled with six liters of previously prepared suspension containing $150 \mathrm{~g} / \mathrm{L}$ of calcium hydroxide. This suspension was obtained by hydration of lime coming from the lime kiln of our industrial partner. The reaction begins with bubbling of gas containing $30 \%$ of $\mathrm{CO}_{2}$ and $70 \%$ of $\mathrm{N}_{2}$. In addition, the gas superficial velocity is $0.08 \mathrm{~m} / \mathrm{s}$, while the temperature of the bulk varies between $21.7^{\circ} \mathrm{C}$ and $22.5^{\circ} \mathrm{C}$, (see Figure B.8 in Appendix) by the use of one thermo-regulated bath. In order to avoid heat exchange, the external tube is incased in a tube of insulating material. During most of the time of reaction, the $\mathrm{pH}$ of the liquid phase remains constant at 12.7 due to the rapid dissolution of solid calcium hydroxide.

All along the reaction, samples of slurry are collected and analyzed by X-ray diffraction and SEM: it was found that only one polymorphic form is obtained: calcite [10]. The X-ray diffractograms and SEM images of PCC particles at different times are presented in Appendix D for 5 and 90 minutes samples.

To determine the mass of PCC produced, the samples are then titrated with hydrochloric acid solution $2 \mathrm{M}$. The acid is added to the sample under agitation until the $\mathrm{pH}$ reaches the value of 8 so that the PCC particles are not dissolved. We made sure that the acid titration did not damage the solid calcium carbonate by using the X-ray diffraction analysis and SEM images after the treatment (see Figure D.15 and Figure D.14 in the Appendix). This titration permits thus to consume the lime, in order to have only PCC remained in the suspension.

Once titrated, the samples are filtered on Büchner $(0.45 \mu \mathrm{m})$ and vacuum dried at $30^{\circ} \mathrm{C}$ during 24 hours. The specific surface area is obtained using nitrogen adsorption with the BET method.

The integral calculation has been achieved thanks to the Matlab toolbox.

\subsection{Experimental Measurements}

The carbonation experiments give two characteristic variables of the PCC: mass produced and specific surface area as a function of time (Figure 2 and Figure 3).

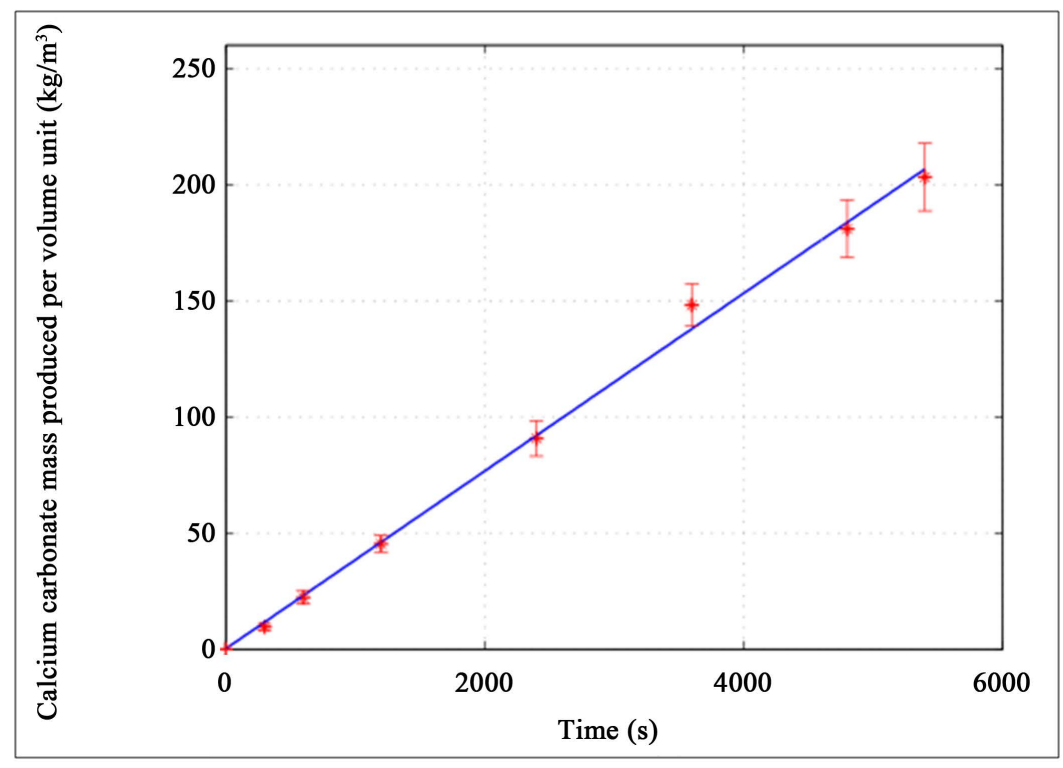

Figure 2. PCC mass production per volume unit vs time. 


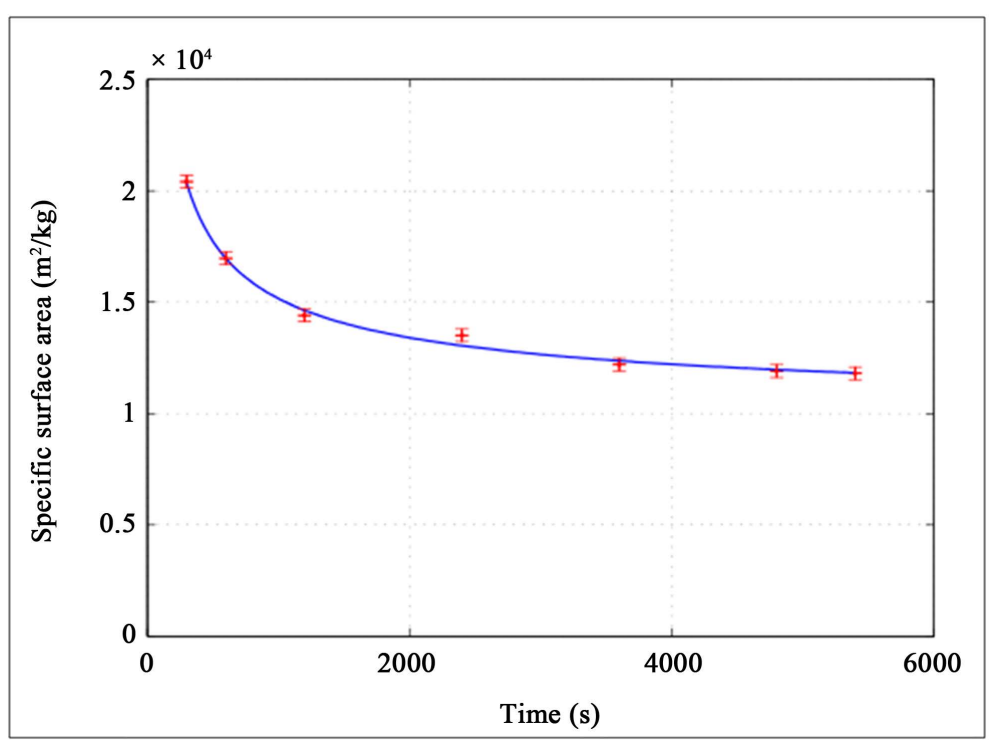

Figure 3. Specific surface area vs time.

\section{Determination of the Nucleation and Crystal Growth Rates}

As mentioned above, during the most part of the carbonation, the $\mathrm{pH}$ of the liquid phase stays around 12.7 before falling down at the end of the reaction. That is why the PCC production rate through $\mathrm{CO}_{2}$ absorption remains constant. The Hatta criterion of this gas-liquid reaction is quite high (around 3, see Appendix). Therefore, $\mathrm{CO}_{2}$ and hydroxyl ions are reacting predominantly in the liquid phase film. The supersaturation in the film is then extremely high and so is the nucleation rate. However, as the film volume is very small in comparison with the suspension volume (ratio close to $10^{-5}$ ), the PCC produced in the film is quickly and strongly diluted in the bulk. Consequently, the supersaturation in the bulk decreases sharply to very low values and the nucleation rate becomes insignificant. The nuclei, formed in the film are now slowly growing in the bulk to give PCC crystals of nanometric size. To resume, the film volume represents principally the nucleation zone while the bulk plays the role of the growth zone. Nevertheless, as the volume of the film is relatively unknown, the nucleation rate will be expressed regarding to the whole suspension volume, which is clearly defined.

The carbonation of the suspension of lime takes place in a batch reactor regarding the suspension. Thus, the precipitation occurs in an environment whose supersaturation is conditioned by the chemical reaction. As written above, the reaction conditions in the film remain constant during the carbonation, so we think that the PCC mass production rate and nucleation rate are probably constant, but these hypotheses must be proved by the experiments. On the contrary, the total surface of the crystals increases with time consuming more calcium carbonate from the solution, so the supersaturation decreases, decreasing at the same time the crystal growth rate. During the carbonation process, the suspension volume remains almost constant. The population balance is exactly the same as the population balance of a batch precipitator with only the difference concerning the third moment, which is imposed by the chemical reaction.

In the case of a batch reactor, the population balance in moments is as follows:

$$
\left\{\begin{array}{l}
\frac{\mathrm{d} m_{0}}{\mathrm{~d} t}=r_{N} \\
\frac{\mathrm{d} m_{k}}{\mathrm{~d} t}=k G m_{k-1} \\
m_{k}(0)=0 \text { with } k=1,2,3, \cdots
\end{array}\right.
$$

where $m_{k}$ are the moments of order " $k$ ", while $r_{N}$ and G are the nucleation and growth rates, respectively.

Figure 2 shows that the PCC mass production rate $r_{M}$ is constant during the carbonation, so the first hypothesis is verified by the experiments. The statistic treatment gives $r_{M}=0.0383 \mathrm{~kg} \cdot \mathrm{m}^{-3} \cdot \mathrm{s}^{-1}$ with a correlation coeffi- 
cient $R^{2}=0.972$. In addition, Figure 3 shows that the specific surface area decreases, because (as noted above) the PCC monoparticles are growing with time. The statistic treatment proposes an empirical equation, which is in very good agreement with the experimental results (Figure 3) with a correlation index $R^{2}=0.995$ :

$$
a_{s}\left(\mathrm{~m}^{2} \cdot \mathrm{kg}^{-1}\right)=\frac{2.456 \times 10^{5}}{t^{0.555}}+9670
$$

Based on the definition, the specific surface area is given by Equation (3):

$$
a_{s}\left(\mathrm{~m}^{2} \cdot \mathrm{kg}^{-1}\right)=\frac{\phi_{S} m_{2}}{\phi_{V} \rho_{C} m_{3}}=\frac{\phi_{S}}{\phi_{V} \rho_{C}} \frac{1}{\frac{m_{3}}{m_{2}}}=\frac{\phi_{S}}{\phi_{V} \rho_{C}} \frac{1}{L_{3,2}}
$$

where $\rho_{C}$ is the calcium carbonate crystal density $\left(2700 \mathrm{~kg} \cdot \mathrm{m}^{-3}\right), L_{3,2}$ represents the Sauter mean diameter, while $\phi_{S}$ and $\phi_{V}$ are the surface and volume shape factors of calcium carbonate monoparticles, respectively.

From Equation (3), there is:

$$
m_{2}=\frac{\phi_{S}}{\phi_{V} \rho_{C}} a_{s} m_{3}
$$

According to the definition of the PCC mass production rate:

$$
r_{M}=\phi_{V} \rho_{C} \frac{\mathrm{d} m_{3}}{\mathrm{~d} t}
$$

the moment of the third order is obtained:

$$
m_{3}=\frac{r_{M}}{\phi_{V} \rho_{C}} t
$$

and:

$$
m_{2}=\frac{r_{M}}{\phi_{S}} a_{S} t
$$

By substituting Equation (5), Equation (6) and Equation (7) in Equation (1) for $k=3$, the expression to calculate the crystal growth rate from experimental results appears:

$$
G=\frac{1}{3} \frac{\phi_{S}}{\phi_{V} \rho_{C}} \frac{1}{a_{S} t}=\frac{1}{3} \frac{\phi_{S}}{\phi_{V} \rho_{C}} \frac{1}{z}
$$

where

$$
Z=a_{S} t=2.546 \times 10^{5} t^{0.445}+9670 t
$$

In a similar manner, from Equation (1) for $k=2$ :

$$
m_{1}=\frac{1}{2 G} \frac{\mathrm{d} m_{2}}{\mathrm{~d} t}=\frac{3}{2} \frac{\phi_{V} \rho_{C}}{\phi_{S}^{2}} \mathrm{zz}^{\prime}
$$

and for $k=1$ :

$$
m_{0}=\frac{1}{G} \frac{\mathrm{d} m_{1}}{\mathrm{~d} t}=\frac{9}{2} \frac{\phi_{V}^{2} \rho_{C}^{2}}{\phi_{S}^{3}} z\left[\left(z^{\prime}\right)^{2}+z z^{\prime \prime}\right]
$$

Lastly, the nucleation rate is obtained for $k=0$ :

$$
r_{N}=\frac{\mathrm{d} m_{0}}{\mathrm{~d} t}
$$

and

$$
r_{N}=\frac{9}{2} \frac{\phi_{V}^{2} \rho_{C}^{2}}{\phi_{S}^{3}} r_{M}\left[\left(z^{\prime}\right)^{3}+4 z z^{\prime} z^{\prime \prime}+z^{2} z^{\prime \prime \prime}\right]
$$


where $z^{\prime}, z^{\prime \prime}$ and $z^{\prime \prime \prime}$ are the first, second and third derivatives of $z$ (Equation (9)). Equation (8), Equation (9) and Equation (12) allow to calculate the nucleation and crystal growth rates from the only two experimental data which are $r_{M}$ and the function $a_{S}(t)$. The PCC particles are synthesized under the polymorphic form calcite, whose crystallographic type is rhombohedric. Based on the definition of the volume equivalent sphere diameter it derives $\phi_{V}=\pi / 6$ and after some geometrical calculations, $\phi_{S}=4.35$ is found for the rhombohedric calcite. These values are used in Equation (8) and Equation (12) for graphical presentation of the crystal growth and nucleation rates in Figure 4 and Figure 5, respectively. As expected, the crystal growth rate decreases sensibly during the carbonation process, while the nucleation rate remains almost constant in the greater part of the process time. The suspension of calcium hydroxide is not viscous, but at the beginning of the reaction, during several minutes, the viscosity increases so much that the suspension becomes like a gel. The reacting system is very complex and no information can be obtained during this period concerning the produced mass of calcium carbonate and its specific surface area. At the end of this first period a slightly higher nucleation rate is observed, which converges rapidly to its constant value corresponding to the stationary chemical absorption.

\section{Particle Size Distribution Characteristics of Agglomerated Calcium Carbonate Nanoparticles}

During the carbonation of lime, small "loose" agglomerates of PCC are obtained not exceeding the size of 10 $\mu \mathrm{m}$. Indeed, when used as filler in plastic and rubber materials, the agglomerates are easily disintegrated in elementary particles whose sizes distribution characterizes the filler properties. The determination of the calcium carbonate mass production rate and the specific surface area as a function of time allow the calculation of

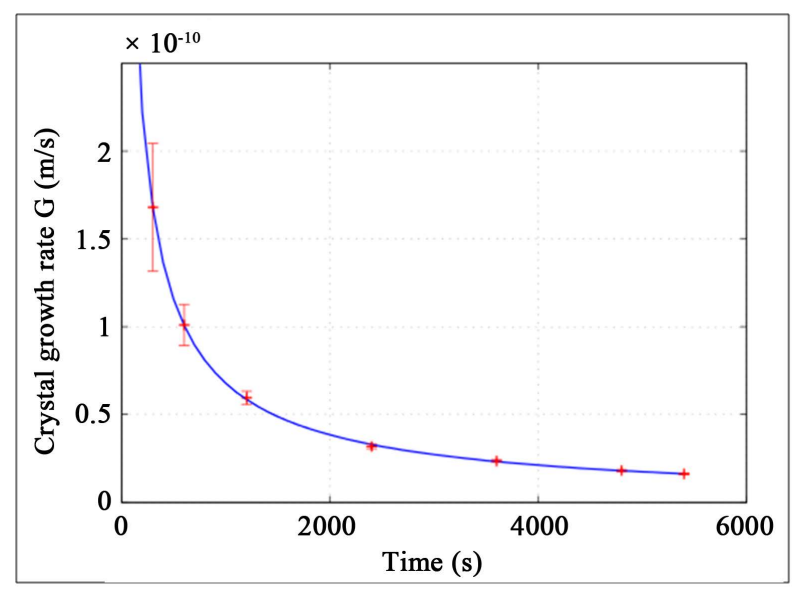

Figure 4. Crystal growth rate vs time.

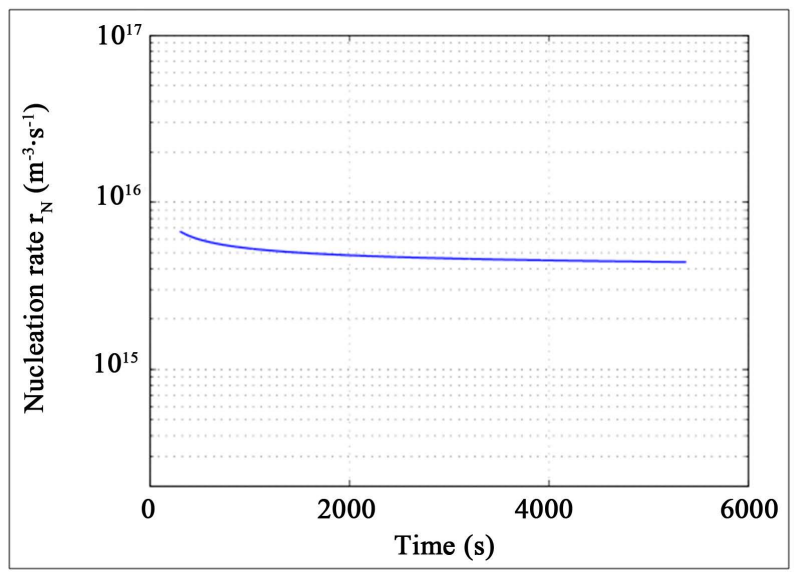

Figure 5. Nucleation rate vs time. 
different mean particle sizes of elementary particles, which represent the essential parameters in corresponding specific applications.

First, the Sauter mean diameter is directly obtained from Equation (3). On the other part, the fourth order moment can be obtained from the Equation (1) for $k=4$ :

$$
m_{4}=4 \int_{0}^{t} G m_{3} \mathrm{~d} t=\frac{4}{3} \frac{\phi_{S}}{\phi_{V}^{2} \rho_{C}^{2}} r_{M} \int_{0}^{t} \frac{1}{a_{S}} \mathrm{~d} t
$$

and the mean mass particle size is calculated as:

$$
L_{4,3}=\frac{m_{4}}{m_{3}}=\frac{4}{3} \frac{\phi_{S}}{\phi_{V} \rho_{C}} \frac{1}{t} \int_{0}^{t} \frac{1}{a_{S}} \mathrm{~d} t
$$

Another parameter is the mean mass-number particle size given by the expression:

$$
L_{3,0}=\left(\frac{m_{3}}{m_{0}}\right)^{1 / 3}=0.606 \frac{\phi_{S}}{\phi_{V} \rho_{C}}\left(\frac{1}{a_{S}\left[\left(z^{\prime}\right)^{2}+z z^{\prime \prime}\right]}\right)^{1 / 3}
$$

All these mean values as a function of process time are presented in Figure 6.

In addition, in the same manner as for the fourth order moment, the fifth order moment can be obtained by the integration of the expression $\mathrm{Gm}_{4}$ :

$$
\begin{aligned}
\frac{\mathrm{d} m_{5}}{\mathrm{~d} t} & =5 G m_{4} \Rightarrow m_{5}=5 \int_{0}^{t} G(t) m_{4} \mathrm{~d} t \\
m_{5} & =5 \int_{0}^{t}\left(\frac{1}{3} \frac{\phi_{S}}{\phi_{V} \rho_{C}} \frac{1}{a_{S}(t) t}\right) m_{4} \mathrm{~d} t
\end{aligned}
$$

and

$$
m_{5}=\frac{20}{9} \frac{\phi_{S}^{2}}{\phi_{V}^{3} \rho_{C}^{3}} r_{M} \int_{0}^{t}\left[\frac{1}{a_{S}(t) t}\left(\int_{0}^{t} \frac{1}{a_{S}(t)} \mathrm{d} t\right)\right] \mathrm{d} t
$$

The coefficient of variation can be calculated as:

$$
C V=\sqrt{\frac{m_{3} m_{5}}{m_{4}^{2}}-1}
$$

The coefficient of variation as a function of time is presented in Figure 7. This parameter is very important

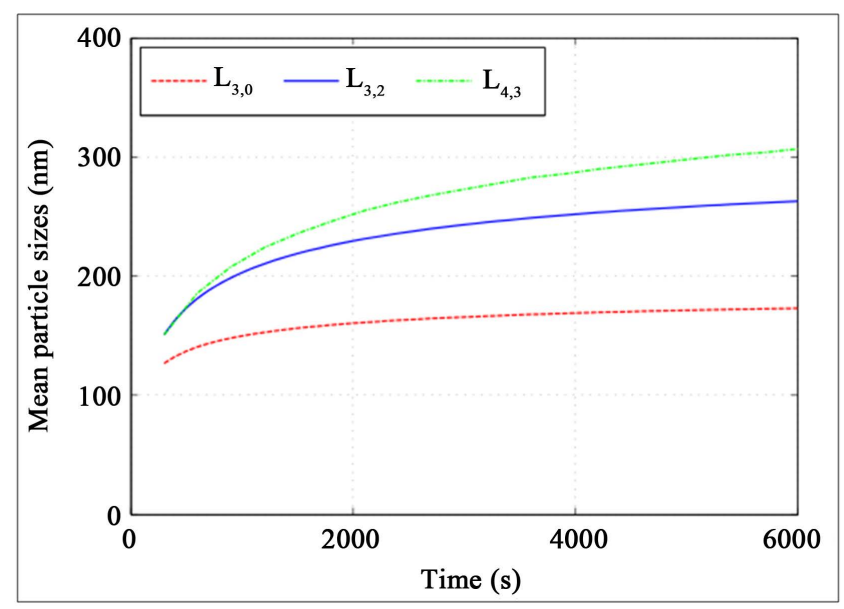

Figure 6. Different mean particle sizes vs time. 


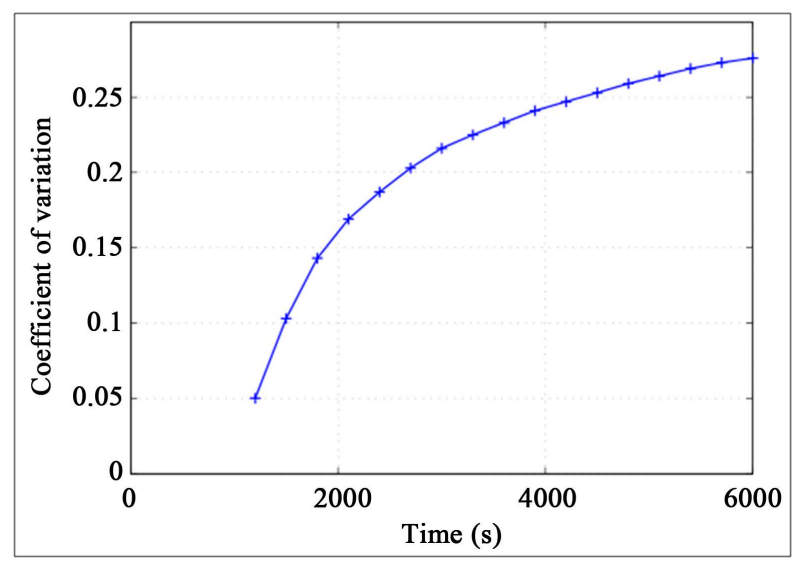

Figure 7. Coefficient of variation of mass monoparticle size distribution vs time.

concerning the quality of the product, because it characterizes the narrowness of the distributions. For example, for $0<\mathrm{CV}<0.2$ the distribution is considered narrow, for $0.2<\mathrm{CV}<0.5$ moderately large, for $0.5<\mathrm{CV}<1$ the distribution is considered large and for $\mathrm{CV}>1$ extralarge. In our case, Figure 6 and Figure 7 show that at the end of the process, the mean mass monoparticle size of precipitated calcium carbonate is about $300 \mathrm{~nm}$ and the coefficient of variation of the mass particle size distribution is 0.28 . These values present valuable information to be known by the industrial users of PCC.

\section{Discussion}

During most of the time of carbonation of a concentrated slurry of calcium hydroxide by bubbling of a gas containing $\mathrm{CO}_{2}$, the $\mathrm{pH}$ of the liquid phase remains constant at 12.7, because the dissolution of solid calcium hydroxide is more rapid than the consumption by chemical reaction of soluble calcium hydroxide. The absorption with chemical reaction (Ha criterion higher than 3) takes place under constant hydrodynamic and chemical conditions (constant $\mathrm{OH}^{-}$ions concentration), so the $\mathrm{CO}_{2}$ mass transfer rate and consequently the mass production rate of calcium carbonate are constant, which is experimentally proved as shown in Figure 2. Practically, all calcium carbonate is produced in the liquid film $(\mathrm{Ha} \geq 3)$ an after that, it diffuses in the bulk, where the nonprecipitated calcium carbonate is highly diluted. As mentioned earlier, the liquid film has a very low volume ( $10^{-5}$ of all suspension volume), thus the supersaturation is very high and constant during the experimental time, because the production rate of calcium carbonate is constant. On the contrary, in the bulk, the supersaturation is very low due to two phenomena: the dilution and the consumption by crystal growth on the surface of the existing calcium carbonate particles. The increase of the number of calcium carbonate particles with time lowers the supersaturation. It is proved by the drop versus time of crystal growth rate (Figure 4), which is an indicator of the supersaturation in the bulk. Indeed, the crystal growth rate is much higher at the beginning of the reaction (small quantity of solid calcium carbonate in the bulk) than in the rest of time when the quantity of produced solid calcium carbonate is sensibly increased. There is a very strong difference between the supersaturation value in the liquid film and in the bulk. The difference is so high that the nucleation takes place principally in the film, while the crystal growth-in the bulk, in spite of the fact that the volume of the bulk is much more important than the volume of the film. As developed in the third section, the nucleation rate is expressed in relation to the whole suspension volume, because the volume of the film is not exactly known. Strictly speaking, the measured mean nucleation rate is:

$$
r_{N, \text { mean }}=\frac{r_{N, \text { film }} V_{\text {film }}+r_{N, \text { bulk }} V_{\text {bulk }}}{V_{\text {film }}+V_{\text {bulk }}}
$$

Only at the beginning of the reaction, the supersaturation in the bulk is one order higher than in the rest of the experiment, so a small increase of the mean nucleation rate is observed (Figure 5), because the production $r_{N, \text { bulk }} V_{\text {bulk }}$ slightly influences the mean nucleation rate. In the rest of the experiment, the $r_{N, \text { bulk }}$ is extremely smaller than $r_{N, \text { film }}$. As a consequence, the second term is negligible and the mean nucleation rate is almost 
constant due to the constant supersaturation and consequently constant value of $r_{N, \text { film }}$ in the liquid film.

\section{Conclusion}

The method presented in this paper allows the determination of nucleation and crystal growth kinetics by following only two macroscopic parameters, i.e. the mass production rate by precipitation and the specific surface area. In addition, it has to be noted that the method is applicable even in the case of very complex media under extreme conditions such as in our case where the system is multi-phasic (gas-liquid-solid) and characterized by a high concentration of solid phase and very intensive gas bubbling. In majority of cases, the products obtained by precipitation are in the form of agglomerates, so the size distribution of elementary particles is practically impossible to be measured. The method presented here can also provide two main characteristics of the monoparticle size distributions, i.e. the mean particle size and the in situ coefficient of variation in agglomerates without destroying them. Indeed, Figure D.12 illustrates the fact that the synthesized PCC monoparticles are nanometric (particles length about $300 \mathrm{~nm}$ ) and with a reaction that lasts 5000 seconds, the crystal growth rate in the bulk has to be very low to observe this size of particles.

\section{Acknowledgements}

Financial support from Solvay Spécialités France is gratefully acknowledged.

\section{References}

[1] Juvekar, V.A. and Sharma, M.M. (1973) Absorption of $\mathrm{CO}_{2}$ in a Suspension of Lime. Chemical Engineering Science, 28, 825-837. http://dx.doi.org/10.1016/0009-2509(77)80017-1

[2] Wachi, S. and Jones, A.G. (1991) Mass Transfer with Chemical Reaction and Precipitation. Chemical Engineering Science, 46, 1027-1033. http://dx.doi.org/10.1016/0009-2509(91)85095-F

[3] Jones, A.G., Hostomsky, J. and Zhou, L. (1992) On the Effect of Liquid Mixing Rate on Primary Crystal Size during the Gas-Liquid Precipitation of Calcium Carbonate. Chemical Engineering Science, 47, 3817-3824. http://dx.doi.org/10.1016/0009-2509(92)85102-H

[4] Hostomsky, J. and Jones, A. (1995) A Penetration Model of the Gas-Liquid Reactive Precipitation of Calcium-Carbonate Crystals. Chemical Engineering Research \& Design, 73, 241-245.

[5] Gomez-Morales, J., Torrent-Burgués, J. and Rodriguez-Clemente, R. (1996) Nucleation of Calcium Carbonate at Different Initial pH Conditions. Journal of Crystal Growth, 169, 331-338. http://dx.doi.org/10.1016/S0022-0248(96)00381-8

[6] Wachi, S. and Jones, A.G. (1992) Dynamic Modelling of Particle Size Distribution and Degree of Agglomeration during Precipitation. Chemical Engineering Science, 47, 3145-3148. http://dx.doi.org/10.1016/0009-2509(92)87016-J

[7] Hostomsky, J. and Jones A. (1991) Calcium-Carbonate Crystallization, Agglomeration and Form during Continuous Precipitation from Solution. Journal of Physics D: Applied Physics, 24, 165-170.

[8] Collier, A.P. and Hounslow, M.J. (1999) Growth and Aggregation Rates for Calcite and Calcium Oxalate Monohydrate. AIChE Journal, 45, 2298-2305. http://dx.doi.org/10.1002/aic.690451105

[9] Lalleman, S., Bertrand, M. and Plasari, E. (2012) Physical Simulation of Precipitation of Radioactive Element Oxalates by Using the Harmless Neodymium Oxalate for Studying the Agglomeration Phenomena. Journal of Crystal Growth, 342, 42-49. http://dx.doi.org/10.1016/j.jcrysgro.2011.01.079

[10] Ricaud, M. (2004) Etude et contrôle du processus d'agregation des particules de carbonate de calcium au cours du proceed de synthèse par carbonatation. Ph.D. Thesis, Université Montpellier II, Montpellier.

[11] Villermaux, J. (1993) Génie de la reaction chimique-Conception et fonctionnement des réacteurs. In: Villermaux, J., Ed., Tech\&Doc, Lavoisier, Paris, 335-345.

[12] Pohorecki, R. and Moniuk, W. (1988) Kinetics of Reaction between Carbon Dioxide and Hydroxyl Ions in Aqueous Electrolyte Solutions. Chemical Engineering Science, 43, 1677-1684. http://dx.doi.org/10.1016/0009-2509(88)85159-5

[13] Franck, M.J.W., Kuipers, J.A.M. and VanSwaaij, W.P.M. (1996) Diffusion Coefficients and Viscosities of $\mathrm{CO}_{2}+\mathrm{H}_{2} \mathrm{O}$, $\mathrm{CO}_{2}+\mathrm{CH}_{3} \mathrm{OH}, \mathrm{NH}_{3}+\mathrm{H}_{2} \mathrm{O}$, and $\mathrm{NH}_{3}+\mathrm{CH}_{3} \mathrm{OH}$ Liquid Mixtures. Journal of Chemical \& Engineering Data, 41, $297-302$. http://dx.doi.org/10.1021/je950157k

[14] Trambouze, P., VanLandeghem, H. and Wauquier, J. (1984) Les réacteurs chimiques—Conception, calcul et mise en oeuvre. In: Trambouze, P., VanLandeghem, H. and Wauquier, J., Eds., Technip, Paris, 284-291. 


\section{Appendix A. Preliminary Study of the Gas-Liquid Conditions}

The Hatta number was calculated thanks to a transfer equation with a chemical reaction like following [11]:

$$
H a^{2}=\frac{\left(2 k \mathrm{Ca}(\mathrm{OH})_{2} D_{\mathrm{CO}_{2}}\right)}{k_{L}^{2}}
$$

where:

- $\quad \mathrm{k}$ is the kinetic constant of the chemical reaction between hydroxyl ions and carbon dioxide [12]:

$$
k=7.1 \times 10^{3} \mathrm{~m}^{3} \cdot \mathrm{kmol}^{-1} \cdot \mathrm{s}^{-1} \text { at } 22^{\circ} \mathrm{C}
$$

- $\quad C_{\mathrm{Ca}(\mathrm{OH})_{2}}$ is the solubility of calcium hydroxide [10]:

$$
C_{\mathrm{Ca}(\mathrm{OH})_{2}}=21.8 \mathrm{~mol} \cdot \mathrm{m}^{-3} \text { at } 22^{\circ} \mathrm{C}
$$

- $\quad D_{\mathrm{CO}_{2}}$ is the diffusivity of carbon dioxide [13]:

$$
D_{\mathrm{CO}_{2}}=1.9 .10^{-9} \mathrm{~m}^{2} \cdot \mathrm{s}^{-1} \text { at } 22{ }^{\circ} \mathrm{C}
$$

- $\quad k_{L}$ is the mass transfer coefficient [14]:

$$
k_{L}=2 \cdot 6.10^{-4} \mathrm{~m} \cdot \mathrm{s}^{-1} \text { at } 22{ }^{\circ} \mathrm{C}
$$

and with all these values, $\mathrm{Ha}=2.9$ for our system.

\section{Appendix B. Temperature Variation during the Reaction of Carbonation}

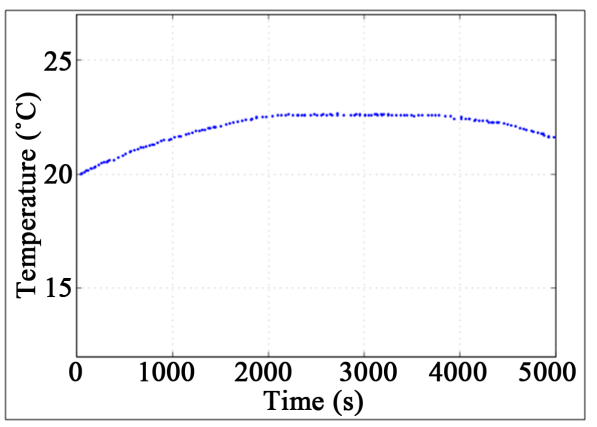

Figure B.8. Temperature of the suspension vs time during the carbonation.

Appendix C. Particle Size Distribution of the Agglomerates

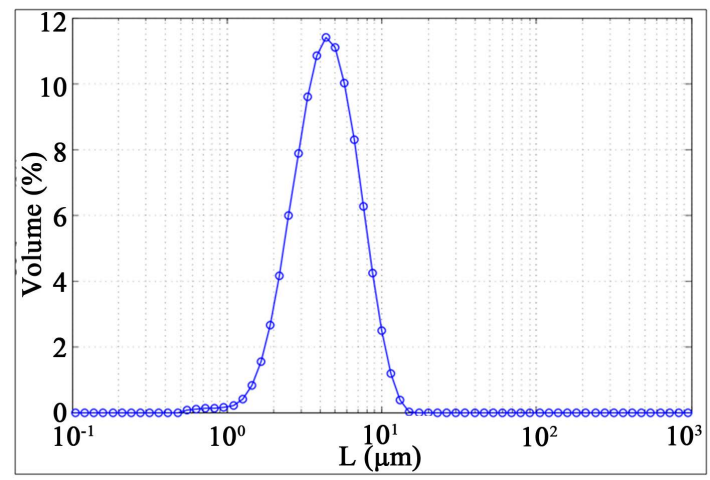

Figure C.9. Particle size distribution of the PCC agglomerates at the end of carbonation. 


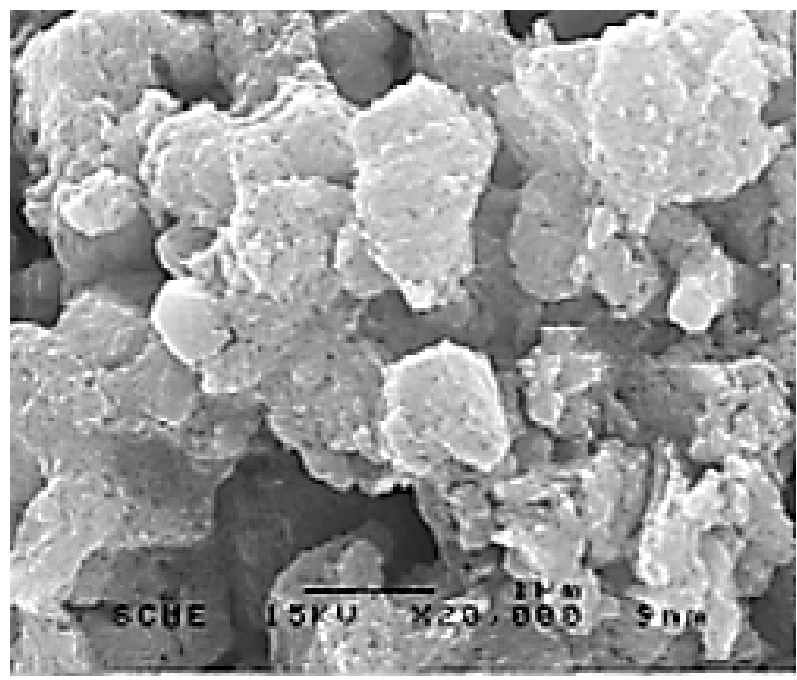

Figure D.10. SEM image at $5 \mathrm{~min}$.

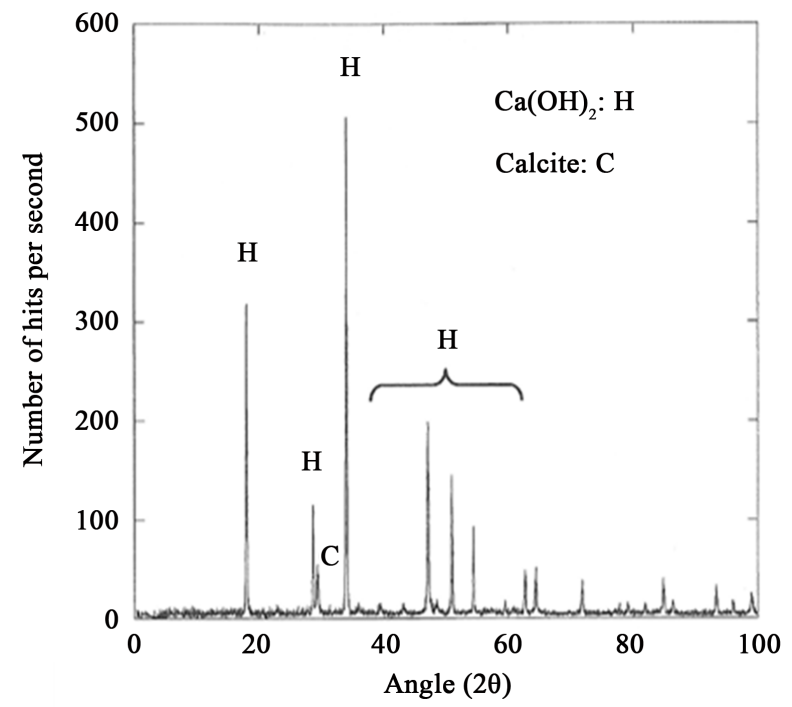

Figure D.11. X-ray image at $5 \mathrm{~min}$.

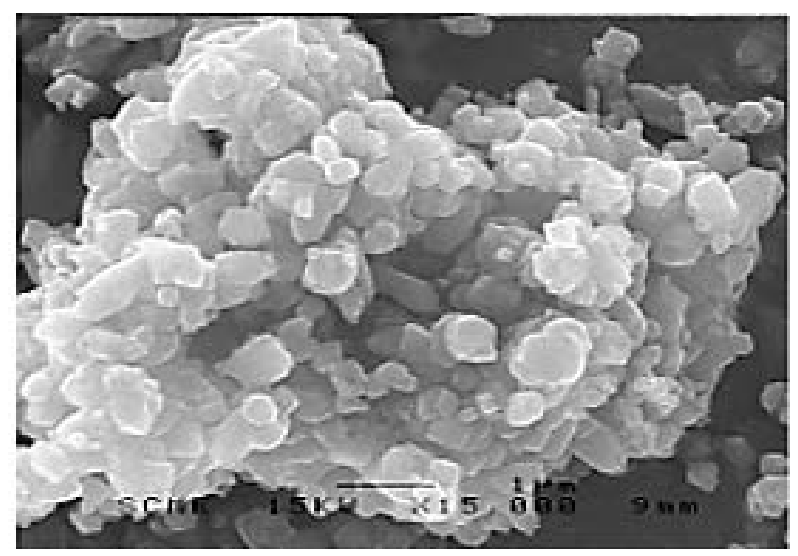

Figure D.12. SEM image at $90 \mathrm{~min}$. 


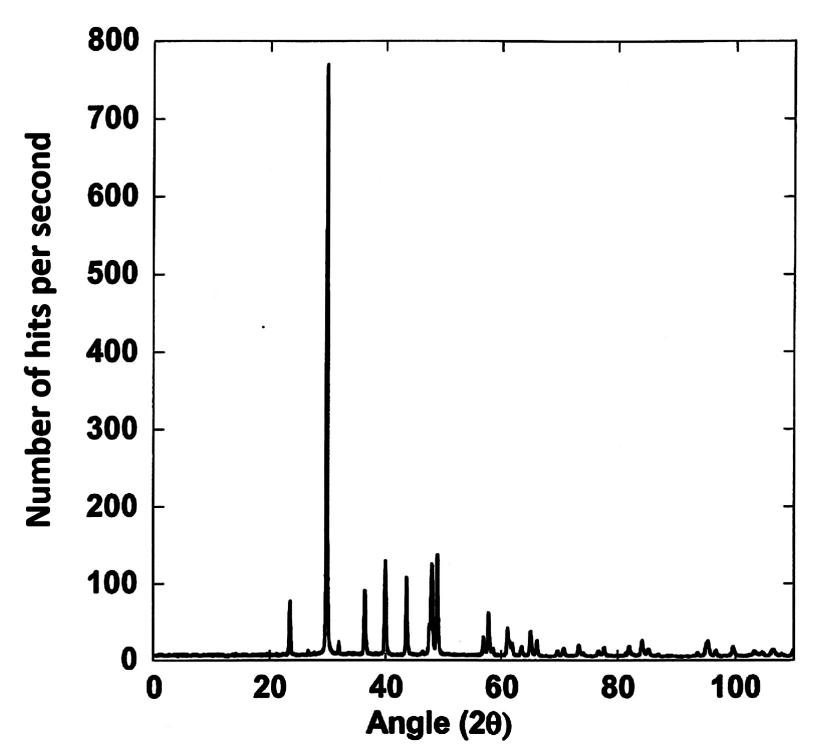

Figure D.13. X-ray image at $90 \mathrm{~min}$ : calcite.

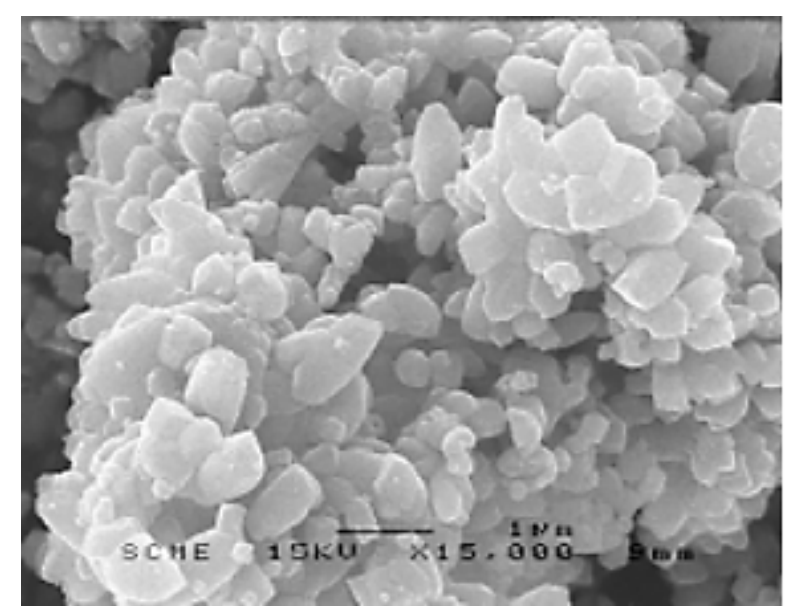

Figure D.14. SEM image of PCC after the acid titration.

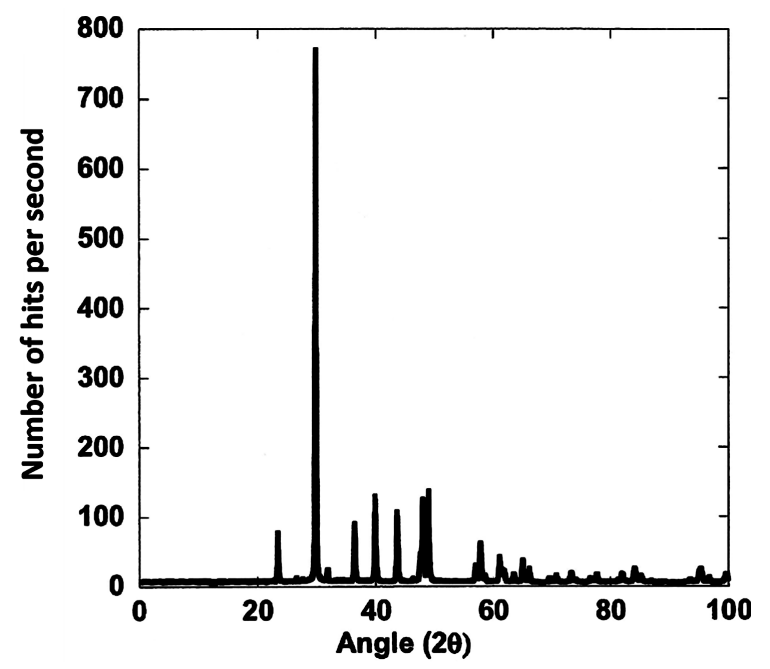

Figure D.15. X-ray image of PCC after the acid titration : calcite. 